\title{
Humidity Induced Defect Generation and Its Control during Organic Bottom Anti-reflective Coating in the Photo Lithography Process of Semiconductors
}

\author{
Seong-Yeol Mun ${ }^{1}$, Seong-Jun Kang ${ }^{2}$, and Yang-Hee Joung ${ }^{2 *}$, Member, KIICE \\ ${ }^{1}$ Department of Foundries FAB, Globalfoundries Silicon Partners Pte. Ltd., Woodland 738406, Singapore \\ ${ }^{2}$ Department of Electrical and Semiconductor Engineering, Chonnam National University, Yeosu 550-749, Korea
}

\begin{abstract}
Defect generation during organic bottom anti-reflective coating (BARC) in the photo lithography process is closely related to humidity control in the BARC coating unit. Defects are related to the water component due to the humidity and act as a blocking material for the etching process, resulting in an extreme pattern bridging in the subsequent BARC etching process of the poly etch step. In this paper, the lower limit for the humidity that should be stringently controlled for to prevent defect generation during BARC coating is proposed. Various images of defects are inspected using various inspection tools utilizing optical and electron beams. The mechanism for defect generation only in the specific BARC coating step is analyzed and explained. The BARC defect-induced gate pattern bridging mechanism in the lithography process is also well explained in this paper.
\end{abstract}

Index Terms: Defect generation, Humidity control, Organic bottom anti-reflective coating, Photolithography, Photo resist

\section{INTRODUCTION}

In the wafer manufacturing process, humidity is one of the most important environmental factors in a manufacturing factory that must be controlled to maintain the high quality of wafers. An abnormal humidity level can cause a variety of problems such as corrosion, electric failure [1, 2], severe adhesion degradation [3, 4], and moisture absorption in dielectric materials [5-7].

Conventionally, the importance of the stringent control of the humidity in the photolithography process has been generally emphasized. However, the defect generation problem has never been dealt with before in detail, such as by inspecting defect images with various inspection tools, observing defect trends with the increase of humidity, and identifying the exact defect generation steps and the defect generation mechanism. This paper proceeds to report on all these investigations of the defect generation problem during the photo lithography process including its mechanism.

Organic bottom anti-reflective coating (BARC) has been widely used with the trend towards a miniaturized pattern size for better pattern definition by preventing reflection of photo waves in the photo lithography process. BARC coating is applied using a spin coater at $23^{\circ} \mathrm{C}$ followed by curing bake at $230^{\circ} \mathrm{C}$. The defects are generated during the BARC spin coating step.

Abnormally high humidity in an organic BARC coater can cause the generation of defects during the BARC coating stage. Furthermore, the water component in the BARC film behaves as a blocking etching process, resulting in poly

Received 09 May 2012, Revised 29 May 2012, Accepted 05 June 2012

*Corresponding Author E-mail: jyanghee@jnu.ac.kr 
pattern bridging and under-etching during the poly etch step.

No other process steps, such as the BARC bake and the PR coating and bake step, are found to create the defectsonly the BARC coating step. The contact angles after each of the process steps are evaluated to explain the reason why the defects are generated only in the BARC coating step. The increasing trend in defect generation with the increase of humidity of the BARC coating unit is also analyzed to identify the lower limit that should be stringently controlled to prevent defect generation. The defects were inspected with various inspection tools in blanket wafers and product wafers to identify them exactly using different inspection tools.

\section{EXPERIMENT}

An (100)-oriented p-type wafer with a resistivity of 9-12 $\Omega$-cm was cleaned by 1:19 diluted hydro fluorine and shallow trench isolation was formed. After WELL and threshold voltage adjustment implantation, gate oxide was grown in a conventional furnace at $800^{\circ} \mathrm{C}$ with wet oxidation targeting $65 \AA$ and $30 \AA$ for high and low voltage areas, respectively. Following the gate oxide growth, undoped polysilicon (poly-Si) was deposited at $530^{\circ} \mathrm{C}$ with $2,500 \AA$. Photo lithography for the gate patterning was performed with a 0.18 um line width using $248 \mathrm{~nm} \mathrm{KrF}$ lithography technology after organic BARC (DUV32J; Brewer Science, Rolla, MI, USA) and photoresist (PR) (SR540; Stanford Research Systems, Sunnyvale, CA, USA) coating targeting $750 \AA$ and $7,600 \AA$, respectively. A decoupled plasma source (DPS) plasma etching reactor was used for the BARC and poly-Si gate etching process. Fig. 1 shows a detailed process schematic diagram.

The coating step is performed in the following sequence: BARC coating at $23^{\circ} \mathrm{C}$, curing bake at $230^{\circ} \mathrm{C}$, PR coating at $23^{\circ} \mathrm{C}$, and curing bake at $120^{\circ} \mathrm{C}$. After each of the coating and bake steps, the defects are inspected to identify the defect generation step and root cause. No patterned wafer defect inspector (Surfscan6200; KLA-Tencor, Milpitas, CA, USA) was used to inspect the defects in the blanket silicon wafer.

Scanning electron microscopy was used to inspect the defect sites and to find the defect sources. The defect count with the increase of humidity during the BARC coating step was also measured at the product wafers with 0.18 um line width using the patterned wafer defect inspector (AIT, KLA-Tencor) and in the blanket wafer using the Surfscan6200. A microscope and ultraviolet (UV) light projector were also used to find a method for identifying the defects with the different sources. The humidity was controlled by a temperature and humidity controller at the BARC coating unit.
The structure of the BARC coating unit is analyzed to explain why the defects were distributed along the wafer edge. The contact angle for the PR (UV113; Shipley, Marlborough, MA, USA) and organic BARC (DUV30J; Brewer Science) film was measured at different steps to identify the defect generation mechanism using a drop shape analysis system (DSA-100; KRUSS GmbH, Hamburg, Germany).

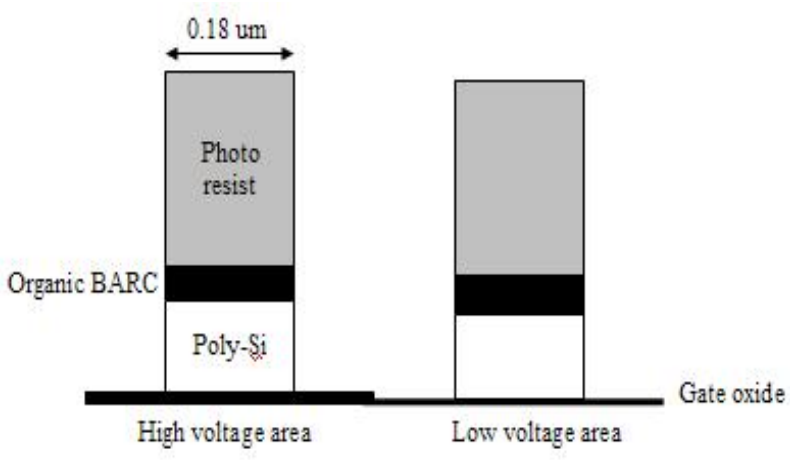

Fig. 1. Process schematic diagram for the gate formation. BARC: bottom anti-reflective coating, Poly-Si: polysilicon.

\section{RESULTS AND DISCUSSION}

Extreme round-type defects were detected right after the gate photo lithography process, which uses organic BARC (DUV32J), at the wafer edge as shown Fig. 2a. The defects induced extreme pattern bridges in the subsequent BARC etching process as shown in Fig. $2 b$.

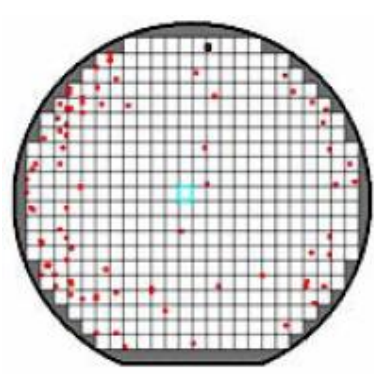

(a)

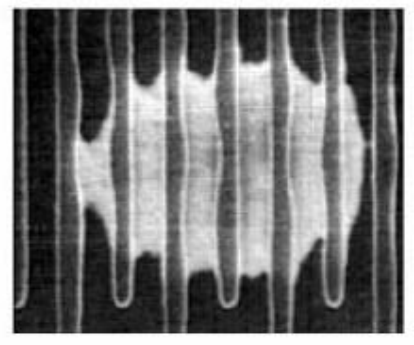

(b)
Fig. 2. (a) Defect distribution map inspected by AIT in the product wafer and (b) scanning electron microscopy image of gate pattern bridging after bottom anti-reflective coating (BARC) etch by BARC defect.

The defect image has a typical shape that can be seen at the viscous source of strong surface tension with the contacted gate patterns as seen Fig. 2b. It can be assumed that the defect is closely related to humidity during the photo lithography process. Evaluation results show the 
defects are created right after PR coating before the exposure step as shown in Fig. 3. The gate photo lithography process of 0.18 um technology is composed of the following steps: BARC coating at $23^{\circ} \mathrm{C}$, curing bake at $230^{\circ} \mathrm{C}$, PR coating at $23^{\circ} \mathrm{C}$, curing bake at $120^{\circ} \mathrm{C}$, exposure, post exposure bake at $130^{\circ} \mathrm{C}$, development and hard bake at $110^{\circ} \mathrm{C}$.

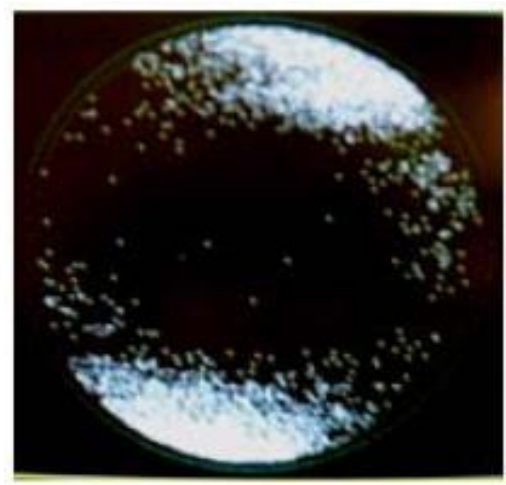

Fig. 3. Defect distribution in blanket wafer viewed by ultraviolet light projector right after photoresist coating step before exposure step

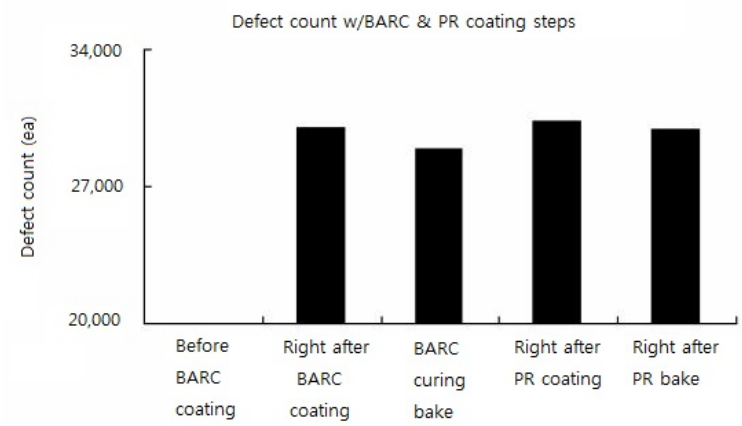

Process steps

Fig. 4. Defect counts measured using Surfscan 6200 in the blanket wafer at each film coating step under $50 \%$ humidity in the coating units. BARC: bottom anti-reflective coating, PR: photoresist.

The BARC coating step is found to be the root cause step in which the defects are created as exhibited in Fig. 4.

The defect count remains unchanged from the subsequent BARC bake step with no more increase. A drastic defect increase is found beginning at $47 \%$ humidity during BARC coating as shown in Figs. 5 and 6 inspected by the Surfscan6200 and microscope, respectively. The results from the blanket wafer and product wafer show exactly the same results.

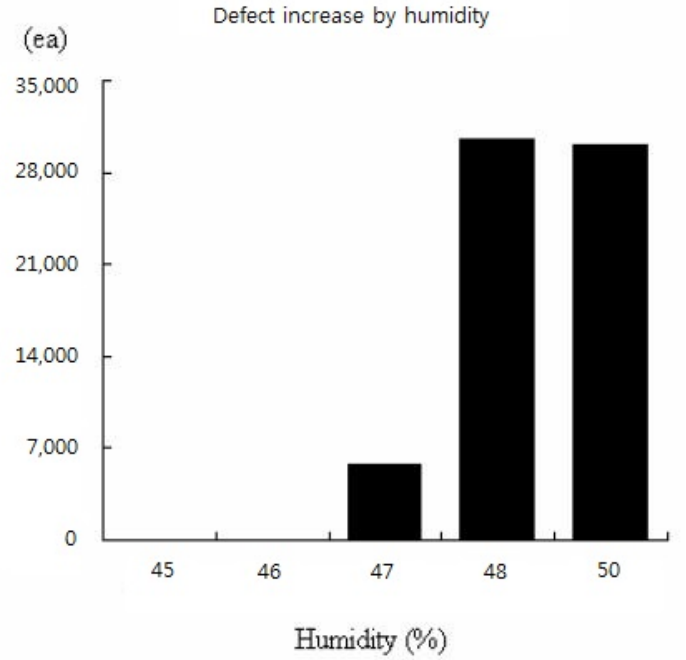

Fig. 5. Defect counts with the increase of humidity of bottom antireflective coating unit, measured by Surfscan6200 at blanket wafer.

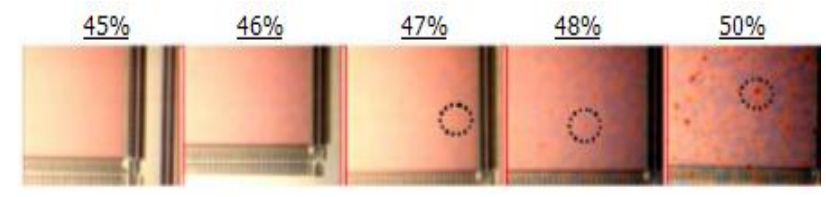

Fig. 6. Defect distribution in the product wafer, inspected through a microscope right after bottom anti-reflective coating (BARC), with the increase of the humidity of the BARC coating step.

The extreme defect generation right after the BARC coating step can be explained by the hydrophilic property of the BARC film at this step. The narrow contact angle for the BARC film right after coating as shown in Fig. 7 means a more hydrophilic property. The wide contact angle for the subsequent BARC curing bake represented hydrophobicity, resulting in a lack of defect generation, as exhibited in Table 1 and Fig. 4.

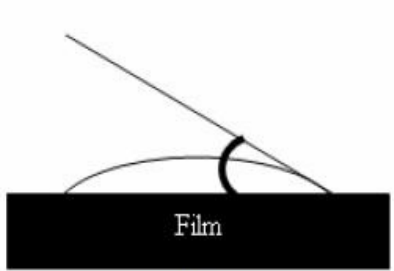

(a)

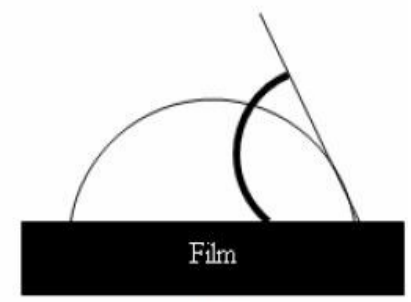

(b)
Fig. 7. Schematic diagram of the relationship between contact angle and the hydrophilic property of the film surface: (a) narrow and (b) wide contact angle. 
The hydrophilic BARC of the narrow contact angle can easily absorb, combine, and react with water creating condensed hydro-organic compounds containing water, whereas hydrophobic BARC after the bake or PR right after coating is unwilling to absorb the water, resulting in no more defect generation. Table 1 and Fig. 4 show that more hydrophilic films generate more defects. A noticeable increase in the contact angle between the coated BARC and baked BARC indicated the hydrophilic property of BARC film before the bake step and hydrophobic property after the bake step through condensation [8]. No difference in contact angle between the coating and bake was found in the case of $\mathrm{PR}$, which is originally a hydrophobic film as explained in Table 1.

Table 1. The Contact angles of bottom anti-reflective coating (BARC)

\begin{tabular}{lcccc}
\hline \multirow{2}{*}{ Step } & \multicolumn{2}{c}{ BARC } & \multicolumn{2}{c}{ PR } \\
\cline { 2 - 5 } & $\begin{array}{c}\text { After } \\
\text { coating }^{\mathrm{a}}\end{array}$ & $\begin{array}{c}\text { After curing } \\
\text { bake }^{\mathrm{b}}\end{array}$ & $\begin{array}{c}\text { After } \\
\text { coating }^{\mathrm{c}}\end{array}$ & $\begin{array}{c}\text { After } \\
\text { bake }^{\text {d }}\end{array}$ \\
\hline Process temperature $\left({ }^{\circ} \mathrm{C}\right)$ & 23 & 230 & 23 & 110 \\
Contact angle $\left({ }^{\circ}\right)$ & 62 & 73 & 69 & 69.2 \\
\hline
\end{tabular}

${ }^{\text {a }}$ Right after coating, ${ }^{\mathrm{b}}$ after pre-bake, ${ }^{\mathrm{c}}$ curing bake, and ${ }^{\mathrm{d}}$ photoresist (PR) right after coating.
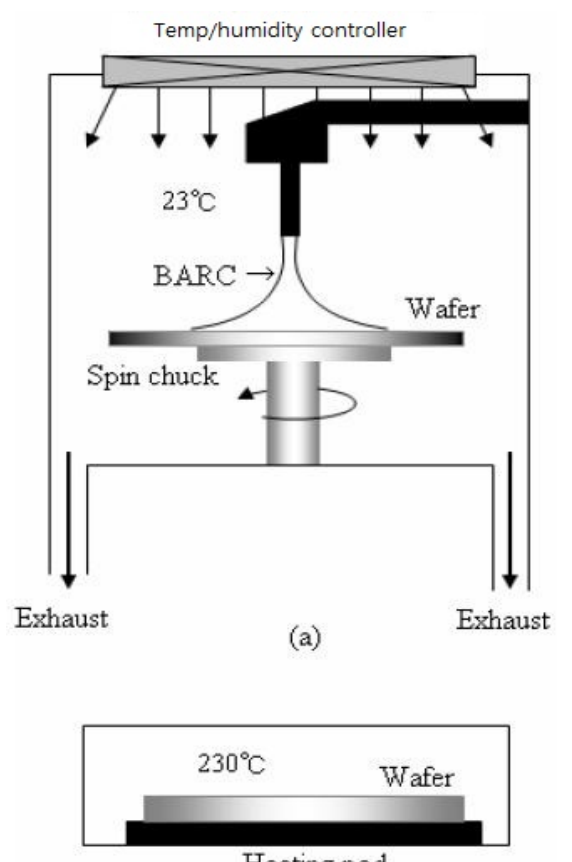

(b)

Fig. 8. Schematic structure of the bottom anti-reflective coating (BARC) units of the coating (a) and curing bake (b).
The defects related to the water component act as a blocking material for the etching process, resulting in an extreme poly line pattern bridging by preventing the etching of the BARC film.

The defect map distributed around the wafer edge is estimated to be caused by the exhaust port surrounding the wafer edge in the BARC coating unit as exhibited in Fig. 8. The moisture flows out to the wafer edge by the exhaust pressure directed to the edge of the BARC unit, resulting in higher moisture density around the wafer edge compared to the center area.

Experimental results indicated that during organic BARC coating process the humidity needed to be maintained below $47 \%$ to prevent moisture-related defect generation as Fig. 5 clearly shows.

\section{CONCLUSIONS}

It was found that an extreme defect is created during the BARC coating before the bake, resulting in pattern bridges. Defects are distributed along the wafer edge due to the location of the exhaust port surrounding the wafer edge in the BARC coating unit. The water can thoroughly combine and react with the BARC film with its hydrophilic property right after coating and before the bake. However, the condensed BARC after the bake converts it to a hydrophobic state, which is reluctant to react with water, suppressing the high humidity-induced defect generation. PR is also hydrophobic enough not to react with water even at the high humidity level of $50 \%$, resulting in no high humidity-associated defect generation.

In sum, humidity must be maintained below $47 \%$ during the BARC coating process to prevent moisture induced defect generation.

\section{REFERENCES}

[1] F. Yeung and Y. C. Chan, "Electrical failure of multilayer ceramic capacitors caused by high temperature and high humidity environment," Proceedings of the 44th Electronic Components and Technology Conference, Washington, DC, pp. 847-853, 1994.

[2] H. C. Ling and A. M. Jackson, "Correlation of silver migration with temperature-humidity-bias (THB) failures in multilayer ceramic capacitors," IEEE Transactions on Components, Hybrids, and Manufacturing Technology, vol. 12, no. 1, pp. 130-137, 1989.

[3] S. Luo and C. P. Wong, "Study on influence of environment on adhesion performance of underfill for flip chip application," Proceedings of International Symposium on Electronic Materials and Packaging, Hong Kong, pp. 243-250, 2000. 
[4] J. C. W. van Vroonhoven, "Effects of adhesion and delamination on stress singularities in plastic-packaged integrated circuits,” Journal of Electronic Packaging, vol. 115, no. 1, pp. 28-33, 1993.

[5] J. V. Champion and S. J. Dodd, "The effect of absorbed water on electrical treeing in epoxy resins," Proceedings of the 7th International Conference on Dielectric Materials, Measurements and Applications, Bath, UK, pp. 206-210, 1996.

[6] M. W. Lane, X. H. Liu, and T. M. Shaw, "Environmental effects on cracking and delamination of dielectric films," IEEE Transactions on Device and Materials Reliability, vol. 4, no. 2, pp. 142-147, 2004.
[7] X. H. Liu, T. M. Shaw, M. W. Lane, R. R. Rosenberg, S. L. Lane, J. P. Doyle, D. Restaino, S. F. Vogt, and D. C. Edelstaeing, "Channel cracking in low-k films on patterned multi-layers," Proceedings of the IEEE International Interconnect Technology Conference, Burlingame, CA, pp. 93-95, 2004.

[8] C. J. Neef, J. Finazzo, C. Nesbit, and M. Weigand, "Effects of bake temperature and surface modifications on hardmask materials for trilayer applications," Proceedings of the SPIE, vol. 6923, pp. 692331, 2008.

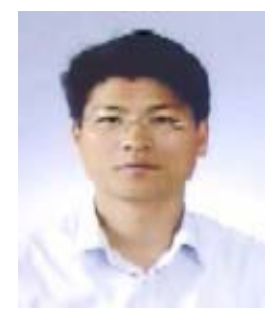

\section{Seong-Yeol Mun}

received the M.S. degree in 2006, and the Ph.D. degree in 2011, both in electrical and semiconductor engineering, from Chonnam National University. He is presently at Globalfoundries Silicon Partners Pte. Ltd., Singapore. His current research interests are process development and improvement of CMOS active pixel image sensors.

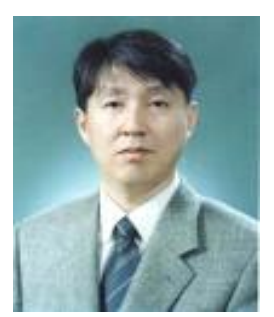

\section{Seong-Jun Kang}

received the M.S. degree in 1994, and the Ph.D. degree in 1999, both in electronic materials and devices engineering, from Inha University. Since 2000, he has been a Professor in the Department of Electrical and Semiconductor Engineering, Chonnam National University, Cheonnam, Korea. His current research interests include semiconductor processing and optical device applications of oxide and II-VI compound semiconductors.

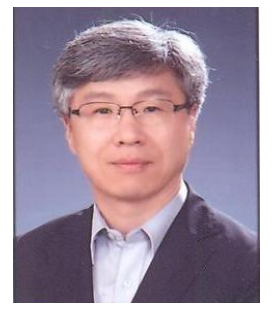

\section{Yang-Hee Joung}

received the M.S. degree in 1985, and the Ph.D. degree in 1993, both in electronic materials and devices engineering, from Inha University. Since 1995, he has been a Professor in the Department of Electrical and Semiconductor Engineering, Chonnam National University, Cheonnam, Korea. His current research interests are semiconductor processing and semiconductor physics. 